\title{
ENCUENTROS DE ALTERIDAD, PEDAGOGÍA Y POLÍTICA
}

\author{
Marcela Ginestet (Universidad Nacional de La Plata)* \\ campitoderetama@yahoo.com.ar \\ Noelia Rozanski (Universidad Nacional de La Plata)** \\ noe.rozanski@gmail.com
}

Recibido: 07/08/2012 Aceptado: 18/11/2012

\section{Introducción}

La diversidad cultural ha sido, desde distintas y en ocasiones antagónicas perspectivas, un tema relevante para la política educativa desarrollada por el Estado argentino desde sus inicios. El proyecto educativo de fines de siglo XIX, consistió en construir una identidad nacional a través de la homogeneización de una sociedad que se presentaba diversa en tres aspectos fundamentales: étnico, cultural y lingüístico. Esta decisión fundante y de la cual quedan huellas, fue puesta en cuestión desde distintas iniciativas que dieran mayor visibilidad a los pueblos indígenas.

La compilación La Educación Intercultural Bilingüe en Argentina (1), de Silvia Hirsch y Adriana Serrudo, presenta en este sentido, trabajos sobre Educación Intercultural Bilingüe -en adelante EIB- situados y desarrollados con colectivos diversos, en distintos contextos de la Argentina.

La primera parte del libro al que referimos, focaliza en la relación entre etnicidad, interculturalidad y políticas educativas. A modo introductorio, las compiladoras realizan un recorrido histórico dando cuenta de los distintos procesos en que se desarrolló la EIB en Argentina, advirtiendo como punto inicial el obje-

* Especialista en Educación con Orientación en Gestión Educativa (UDESA), Profesora en Historia (FaHCE-UNLP). Doctoranda en Ciencias de la Educación (FaHCE-UNLP).

** Diplomatura en Ciencias Sociales con orientación en Gestión de las Instituciones Educativas (FLACSO). Profesora en Ciencias de la Educación (FaHCE-UNLP). Maestranda en Antropología Social (IAES_UN San Martín), becaria de la Comisión de Investigaciones Científicas (IDAES).(España). 
tivo civilizatorio del proyecto educativo decimonónico a través de la imposición de formas de vida legitimadas étnica, lingüística y culturalmente, y valorando la EIB como "modelo alternativo a una educación normativista y a la construcción de una ciudadanía hegemónica" (Hirsch, 2010: 39). Ivanna Petz focaliza en la relación entre Estados Provinciales y educación, comparando las políticas y prácticas educativas en Salta y Formosa, y problematizando el marco legal y la génesis del proceso de EIB en cada provincia, y las prácticas educativas ligadas a ella. Advierte para Formosa mayor desarrollo político destinado a la EIB en relación a la Provincia de Salta, y del mismo modo, gran diferencia de sentidos: la última, asimilacionista; la primera, en diálogo e integración con organizaciones indigenistas latinoamericanas.

Otros trabajos focalizan en experiencias de EIB en contextos urbanos en Santa Fe y Neuquén. Nora Julia Arias establece una relación entre el Consejo de Idioma y Cultura (CIC) de la Escuela 1344 Cacique Taigoyé, el asentamiento toba de Rosario, y la reglamentación de EIB de Santa Fe, bajo el propósito de "tensionar los conceptos de etnicidad, identidad, diversidad social y cultural, utilizados (o no) en este reglamento y en los dictados específicos de la nueva Ley de Educación Nacional" (Arias, 2010: 71). A partir de indagar las visiones ajenas y propias en tanto indígenas de quienes habitan el asentamiento y analizar las prácticas de conformación de la identidad en la escuela, insta a la reflexión sobre el reclamo indígena como problema de la sociedad toda. Ligando la educación a dimensiones territoriales, sociales, políticas y jurídicas, y concibiendo las experiencias educativas interculturales como procesos de construcción colectiva, Raúl Díaz plantea los lineamientos político-pedagógicos de experiencias de EIB en Neuquén, retomando trabajos realizados desde la Universidad Nacional del Comahue.

Los dos capítulos siguientes: un nuevo trabajo de Silvia Hirsch -compiladora de este libro-y otro de Cristóbal Wallis, problematizan sobre las posibilidades de la EIB en contextos pluriétnicos y plurilingüísticos, y en comunidades wichí del Pilcomayo. En el primer caso, la autora realiza un estudio en el departamento de San Martín, Salta, en el cual conviven siete pueblos originarios; así como migrantes de diverso origen. Propone pensar la EIB como un puente de comunicación, proceso complejo en permanente devenir y espacio de construcción de una sociedad más equitativa y democrática. En el segundo caso, Cristóbal Wallis advierte la necesidad de un diagnóstico sobre las posibilidades de la EIB previo desarrollo, así como las particularidades de cada lugar donde tales experiencias tienen lugar, enfatizando en la importancia de la transformación de los esquemas de pensamiento que subyacen a la escuela.

La segunda parte reúne trabajos ligados a los procesos de cambio generados por la EIB en relación a capacitación, formación docente y el diseño de materiales didácticos. En tal sentido, Juan Pablo Cervera Novo analiza la capacitación de auxiliares bilingües y la producción de textos multilingües en 
el Chaco Salteño, centrándose en experiencias de trabajo con auxiliares bilingües wichí, chulupí, chorote y toba del núcleo educativo Santa Victoria, Salta. Considera relevante pensar la EIB ligada al pleno ejercicio de los derechos de las minorías y su reconocimiento por parte de las mayorías hegemónicas. Asimismo, Laureano Borton analiza las representaciones escolares sobre el niño indígena como sujeto de aprendizaje, en Buenos Aires, en una escuela católica; y en Misiones, en un instituto católico del Obispado de Iguazú, ubicado en una comunidad mbyá-guaraní. Mónica Zidarich, analizando la EIB en Chaco, valora el desarrollo de experiencias educativas interculturales bilingües a través de la implementación de parejas pedagógicas conformadas por un docente originario y uno no originario.

Los dos capítulos siguientes: un nuevo trabajo de Adriana Serrudo -compiladora de este libro- y otro de Hugo Arce, focalizan en las representaciones y tensiones acerca de los docentes indígenas bilingües en Argentina y las posibilidades de la Educación Superior Indígena en Misiones. En el primer caso, la autora describe la complejidad de las situaciones vividas por docentes indígenas en la relación cotidiana con sus colegas no indígenas; y advierte los espacios de tensiones y disputas de sentidos en los que se involucran en tanto reflejo de relaciones sociales históricamente establecidas. En el segundo, el autor analiza las experiencias de ingreso de jóvenes guaraníes a estudios universitarios y la propuesta de una Red de Educación Superior Indígena. Propone un trabajo articulado entre instituciones educativas, estado y comunidad, para viabilizar propuestas educativas que desarrolladas en forma aislada, no prosperan.

La tercera parte reúne experiencias educativas centradas en su carácter bilingüe. La primera, consiste en un análisis de la situación sociolingüística y educativa de la Provincia de Corrientes y dos experiencias posibles de ser desarrolladas en este territorio. En este trabajo, Carolina Gandulfo va más allá de la descripción, manifestando la necesidad de procesos de educación bilingüe no solo en las comunidades indígenas sino fuera de ellas también. La segunda, consiste en una reflexión sobre las lenguas en EIB a nivel nacional, advirtiendo la ficción que representa su inclusión en la normativa en tanto que su desarrollo en prácticas educativas bilingües reales raras veces se produce.

Estos trabajos constituyen un sustancial aporte teórico a la educación, para desnaturalizar prejuicios arraigados, pensar que no existe una única forma de educar y abrir posibilidades a propuestas educativas en diálogo con voces "otras", y en un marco de interculturalidad crítica.

\section{Notas Bibliográficas}

- Hirsch, S. y Serrudo, A. (comps.) (2010) Educación Intercultural Bilingüe en Argentina. Buenos Aires: Novedades Educativas 